\title{
HYPOVITAMINOSIS D IN ADULT - A SYSTEMIC REVIEW
}

\author{
QUAZI TARIKUL ISLAM ${ }^{1}$, M ROBED AMIN ${ }^{2}$
}

\begin{abstract}
:
Background: Hypovitaminosis $D$ is now recognized as a pandemic. Vitamin $D$ can be supplied from the dietary sources but is mainly generated endogenously from skin exposure to sunlight via the epidermis, which is the main source of vitamin D synthesis. Despite abundant sunshine,there is high prevalence of hypovitaminosis $D$ in south-east asia and middle east leading to different clinical manifestation including musculoskeletal disorders such as non specific muscle pain, poor muscle strength and low BMD as well as non-musculoskeletal disorders such as increased risk of respiratory tract infections, diabetes mellitus, cardiovascular diseases, auto-immune disorder and cancer. There are multiple factors contributing to the hypovitaminosis $D$ such as extreme of age, female sex, lack of sun exposure, covered clothing style, sunscreen use, skin pigmentation or dark skin, winter season, latitude, malabsorption, anticovulsant drugs, chronic kidney disease, liver disease and obesity.
\end{abstract}

Objectives: To aware doctors, patients, food producers and consumers.

Data source: Online search via Google, 101 articles were down loaded, 69 valid papers were selected. Only 17 full text articles were eligible for review.

Received: 10 October 2016

Accepted: 28 December 2016

\section{Introduction:}

Vitamin-D is a pro-hormone that has a critical role in the phosphocalcic metabolism and sufficient vitamin D levels are essential for optimal bone mineral density. Vitamin D can be supplied from the dietary sources but is mainly generated endogenously from skin exposure to sunlight via the epidermis, which is the main source of vitamin D photosynthesis. In addition, the vitamin $\mathrm{D}$ receptor (VDR) located within the keratinocytes makes these cells a unique photoendocrine vitamin $\mathrm{D}$ system that is stimulated by UVB irradiation. Binding of vitamin D on keratinocyte VDR enhances the production of cathelicidins, which have potent microbicidal activities and are a major component of the innate immune system ${ }^{1}$. Adequuate levels of vitamin D are maintained through cutaneous synthesis on exposure of skin to sunlight ultraviolet B rays $(290-315 \mathrm{~mm})$ and through limited dietary sources (fatty fishes such as salmon, mackerel and sardine, cod liver oil, egg yolk and milk). A number of factors such as duration and time of sun exposure, latitude, season, atmospheric pollution, clothing style, use of sun blocks, skin pigmentation as well as obesity and presence of several chronic diseases influence the photosynthesis and bioavailability of vitamin D status of body ${ }^{2-3}$. The distance that sunlight travels to the earth's atmosphere is the least in regions nearest the equator. Thus, UVB rays are the most intense and vitamin $\mathrm{D}$ synthesis is possible all year long in zones extending between latitudes $23.5^{\circ} \mathrm{N}$ and $23.5^{\circ} \mathrm{S}$ to the equator (the tropics). In latitudes higher than the tropics, the angle of light striking the earth is such that UVB intensely become insufficient for vitamin $\mathrm{D}$ synthesis. In temperate zones $\left(23.5^{\circ}-66.5^{\circ}\right)$ people lack sufficient UVB to synthesize vitamin D for 1 month of the year, whereas those nearer to the poles do not get enough UVB radiation for vitamin $D$ synthesis for most of the year ${ }^{4}$.

Synthesis and Metabolism of Vitamin D in the regulation of Calcium, Phosphorus and bone metabolism;

1. Professor of Medicine, Popular Medical College

2. Associate Porfessor of Medicine, Dhaka Medical College

Address of Correspondence: Dr. Quazi Tarikul Islam, Professor of Medicine, Popular Medical College

Bangladesh J Medicine 2017; $28: 34-40$ 
During exposure to solar ultraviolet B (UVB) radiation, 7-dehydrocholesterol in the skin is converted to previtamin D3, which is immediately converted to vitamin D3 in a heat-dependent process. Excessive exposure to sunlight degrades previtamin D3 and vitamin D3 into inactive photoproducts. Vitamin D2 and vitamin D3 from dietary sources are incorporated into chylomicrons and transported by the lymphatic system into the venous circulation. Vitamin D (hereafter "D" represents D2 or D3) made in the skin or ingested in the diet can be stored in and then released from fat cells. Vitamin D in the circulation is bound to the vitamin D-binding protein, which transports it to the liver, where vitamin $\mathrm{D}$ is converted by vitamin D-25-hydroxylase to 25-hydroxyvitamin D $[25(\mathrm{OH}) \mathrm{D}]$. This is the major circulating form of vitamin $\mathrm{D}$ that is used by clinicians to determine vitamin $\mathrm{D}$ status. (Although most laboratories report the normal range to be 20 to $100 \mathrm{ng}$ per milliliter [50 to $250 \mathrm{nmol}$ per liter], the preferred range is 30 to $60 \mathrm{ng}$ per milliliter [75 to $150 \mathrm{nmol}$ per liter].) This form of vitamin $\mathrm{D}$ is biologically inactive and must be converted in the kidneys by 25-hydroxyvitamin D-1áhydroxylase (1-OHase) to the biologically active form - 1,25-dihydroxyvitamin D [1,25(OH)2D]. Serum phosphorus, calcium, fibroblast growth factor 23 (FGF23), and other factors can either increase $(+)$ or decrease $(-)$ the renal production of $1,25(\mathrm{OH}) 2 \mathrm{D}$. $1,25(\mathrm{OH}) 2 \mathrm{D}$ decreases its own synthesis through negative feedback and decreases the synthesis and secretion of parathyroid hormone by the parathyroid glands. 1,25(OH)2D increases the expression of 25hydroxyvitamin D-24-hydroxylase (24-OHase) to catabolize $1,25(\mathrm{OH}) 2 \mathrm{D}$ to the water-soluble, biologically inactive calcitroic acid, which is excreted in the bile. $1,25(\mathrm{OH}) 2 \mathrm{D}$ enhances intestinal calcium absorption in the small intestine by interacting with the vitamin $\mathrm{D}$ receptor-retinoic acid $\mathrm{x}$-receptor complex (VDR-RXR) to enhance the expression of the epithelial calcium channel (transient receptor potential cation channel, subfamily V, member 6 [TRPV6]) and calbindin 9K, a calcium-binding protein $(\mathrm{CaBP}) .1,25(\mathrm{OH}) 2 \mathrm{D}$ is recognized by its receptor in osteoblasts, causing an increase in the expression of the receptor activator of nuclear factor-êB ligand (RANKL). RANK, the receptor for RANKL on preosteoclasts, binds RANKL, which induces preosteoclasts to become mature osteoclasts. Mature osteoclasts remove calcium and phosphorus from the bone, maintaining calcium and phosphorus levels in the blood. Adequate calcium $(\mathrm{Ca} 2+)$ and phosphorus (HPO42") levels promote the mineralization of the skeleton $^{5}$.
Despite abundant sunshine, there is high prevalence of hypovitaminosis D in Bangladesh leading to different clinical manifestation including musculoskeletal disorders such as non specific muscle pain, poor muscle strength and low BMD as well as non-musculoskeletal disorders such as increased risk of respiratory tract infections, diabetes mellitus and possibly cardiovascular diseases ${ }^{6}$.

Recently it is observed in our day to day practice that many patients coming with non-skeletal generalized aches and pain and diagnosed as fibromyalgia syndrome, but treatment is non-rewarding. On evaluation, it is seen that vitamin D level is low and correction of hypovitaminosis D causes significant improvement of symptoms.

Methods \& Materials: Data and information are taken from on line survey and meta-analysis of multiple journals.

\section{Discussion:}

Rickets in children and osteomalacia in adults are the classic manifestations of profound vitamin D deficiency. In recent years, however, nonmusculoskeletal condi-tions-including cancer, metabolic syndrome, infectious and autoimmune disorders-have also been found to be associated with low vitamin D levels ${ }^{7}$.

\section{Children}

Vitamin D deficiency should be suspected in children with known risk factors who are unwell with pain, irritability, poor growth or skeletal deformity and in all children with a seizure disorder ${ }^{8}$.

\section{Adults}

Pain and proximal muscle weakness dominate the clinical picture of vitamin D deficiency in adults. Rib, hip, pelvis, thigh, and foot pain are typical. More diffuse muscular aches and muscle weakness, including in the limbs and back, are also common and may be labelled as "fibromyalgia" or as a somatisation of depression ${ }^{9}$.

\section{Osteoporosis}

Approximately 33\% of women aged between 60 to 70 and $66 \%$ of those over 80 have osteoporosis. The link between vitamin D deficiency and osteoporosis has been well established especially in the elderly. Vitamin D deficiency is associated with the marked suppression in intestinal $\mathrm{Ca}$ absorption and the impairment of $\mathrm{Ca}$ balance, which results in low bone mineral content and density. Reduced bone mineral density (BMD) increases the risk of fractures, which significantly contributes to morbidity and mortality of older persons ${ }^{10,11}$. 


\section{Autoimmune Diseases, Osteoarthritis and Diabetes} Living at higher latitudes increases the risk of type 1 diabetes, multiple sclerosis, and Crohn's disease ${ }^{12,13}$ Living below 35 degrees latitude for the first 10 years of life reduces the risk of multiple sclerosis by approximately 50\%14,15. Among white men and women, the risk of multiple sclerosis decreased by $41 \%$ for every increase of 20 ng per milliliter in 25hydroxyvitamin D above approximately $24 \mathrm{ng}$ per milliliter (60 nmol per liter) (odds ratio, 0.59; 95\% CI, 0.36 to $0.97 ; \mathrm{P}=0.04) .{ }^{15}$ Women who ingested more than 400 IU of vitamin D per day had a $42 \%$ reduced risk of developing multiple sclerosis. ${ }^{16}$ Similar observations have been made for rheumatoid arthritis and osteoarthritis ${ }^{17}$. Several studies suggest that vitamin D supplementation in children reduces the risk of type 1 diabetes. Increasing vitamin $\mathrm{D}$ intake during pregnancy reduces the development of islet autoantibodies in offspring ${ }^{18}$.

\section{Cardiovascular Disease}

Living at higher latitudes increases the risk of hypertension and cardiovascular disease ${ }^{19}$. In a study of patients with hypertension who were exposed to UVB radiation three times a week for 3 months, 25- hydroxyvitamin D levels increased by approximately $180 \%$, and blood pressure became normal (both systolic and diastolic blood pressure reduced by $6 \mathrm{~mm} \mathrm{Hg})^{20}$. Vitamin D deficiency is associated with congestive heart failure ${ }^{21}$ and blood levels of inflammatory factors, including C-reactive protein and interleukin-10 ${ }^{22}$.

\section{Schizophrenia and Depression}

Vitamin D deficiency has been linked to an increased incidence of schizophrenia and depression ${ }^{23}$. Maintaining vitamin D sufficiency in utero and during early life to satisfy the vitamin $D$ receptor transcriptional activity in the brain, may be important for brain development as well as for maintenance of mental function later in life $^{24}$.

\section{Cancer}

The first study indicating that sunlight exposure may lower the risk of cancer was first made almost seven decades ago. Garland and Garland were the first to propose that vitamin $\mathrm{D}$ deficiency may contribute to a higher risk of colon cancer mortality since vitamin $\mathrm{D}$ is formed in the skin through solar UVB radiation. More recently, the discovery of increased risks of certain types of cancer in those who are vitamin D deficient, suggests that vitamin D deficiency may account for thousands of premature deaths from colon, breast, ovarian and prostate cancer every year.Vitamin $\mathrm{D}$ is one of the most potent hormones for regulating cell growth. It was discovered that many cell types contain vitamin $\mathrm{D}$ receptors. These receptors can be activated by $1,25(\mathrm{OH})_{2} \mathrm{D}$ and induce differentiation into normally functioning cells, and inhibit proliferation, invasiveness, angiogenesis, and metastatic potential. In tumor models such as cancers of the lung, colon, kidney, breast and prostate, vitamin $\mathrm{D}$ played a role in activity against metastasis ${ }^{25}$.

\section{Factors responsible for vitamin D deficiency}

There are many causes of vitamin D deficiency. Generally, they can be divided into two groups: UVBrelated deficiency and medical/physical conditionrelated deficiency.

\section{UVB-related deficiency}

The elderly: The elderly, due to the decreased presence of skin 7-dehydrocholesterol which is the precursor for UVB mediated synthesis of vitamin D, are particularly at risk of vitamin D deficiency. Moreover, reduced mobility or institutionalization that discourages sun exposure, reduced renal production of 1,25-dihydroxyvitamin D as well as decreased intake of fortified foods pose great difficulties in vitamin $\mathrm{D}$ formation in body 26,27 .

Dark skin: People with dark skin have great amounts of melanin in their epidermis. Melanin competes with 7-dehydrocholesterol for absorption of UVB photons. Therefore, people of color are less efficient in producing vitamin $\mathrm{D}$ than are whites. It is reported that a person with skin type $5 / 6$ (dark skin) requires 10-50 times the exposure to sunlight to produce the same amount of vitamin $\mathrm{D}$ as does a white person with skin type $2 / 3^{28}$.

Season, latitude, and the time of day: It has been established that the ozone layer can absorb UVB radiation above $290 \mathrm{~nm}$ which is responsible for generating previtamin D3. Zenith angle, defined as the angle of the sunlight reaching the Earth's surface, decides the thickness of ozone layer which sunlight needs to penetrate. The thicker the ozone layer is, the fewer amounts of UVB photons can reach the earth, thus few previtaminD3 can be produced. Zenith angle is dependent on factors such as time of day, season of the year, and latitude.

Thus those factors have great effects on vitamin $\mathrm{D}$ production 29,30 .

Sunscreen users: Sunscreens can efficiently absorb UVB radiation. This dramatically prevents the interaction of UVB with 7-dehydrocholesterol, the process of previtamin D3 generation. It has been shown that when used. 
properly, a sunscreen with a sun protection factor of 8 reduces the production of previtamin D3 by 95\%, and $99 \%$ by a sun protection factor of $15^{31,32}$.

\section{Medical/physical condition-related deficiency}

Fat malabsorption: As a fat-soluble vitamin, vitamin $D$ requires the presence of dietary fat in the gut for absorption. Certain pathological conditions, such as

Crohn's disease, cystic fibrosis $(\mathrm{CF})$, celiac disease, surgical removal of part of the stomach or intestines are associated with fat malabsorption and thus may lead to vitamin D deficiency. For example, CF patients suffer from pancreatic exocrine insufficiency. This results in malabsorption of fat-soluble vitamins, including vitamin D. CF patients, depending on the degree of exocrine insufficiency, absorb approximately $50 \%$ less vitamin D than normal ${ }^{31}$

Anticovulsant use: Anticonvulsants, also called antiepileptic drugs, have been used to treat epileptic seizures and bipolar disorder. It is well recognized that long-term use of some antiepileptic drugs, including phenobarbital, phenytoin, and carbamazepine and the antimicrobial agent rifampicin (RIF) can result in osteomalacia ${ }^{33,34}$. The induction of the catabolism of 1,25-dihydroxyvitamin $\mathrm{D}$ by these drugs is thought to contribute to their deleterious side effects.

Chronic kidney disease: In order to become biological active vitamin $\mathrm{D}$, kidney plays an important role in this transforming process. Chronic kidney disease such as patients with stage 4 or 5 chronic kidney disease, as well as those requiring dialysis, leads to an inability to make sufficient 1,25dihydroxyvitamin $\mathrm{D}$ which has a direct effect in inhibiting parathyroid hormones expression 35,36]. Thus 1,25-dihydroxyvitamin D3 intake is needed to maintain calcium level in blood as well as to control parathyroid hormone levels.

Obesity: It has been known for a long time that obese people are prone to be vitamin D deficient since they have lower 25-hydroxyvitamin D levels ${ }^{37-40}$.

A number of studies proved that the vitamin D3 precursor 7-dehydrocholesterol levels in the skin of obese people were not significantly different from nonobese people ${ }^{41}$. One explanation was that the subcutaneous fat, which is known to store vitamin $\mathrm{D}$, sequestered more of the cutaneous synthesized vitamin $\mathrm{D}$, which results in less release of vitamin $\mathrm{D}$ from the skin into the circulation in the obese subject than non-obese subject 42 ].

\section{Liver disease}

The liver plays an important role in the maintenance of vitamin D status and hepatobiliary disease is often associated with low levels of 25(OH)D and impaired bone metabolism. In cholestatic liver disease, there is a decrease in the intestinal availability of bile salts. This results in malabsorption of fat-soluble vitamins such as vitamin $\mathrm{D}^{43}$.

\section{Prevalence of hypovitaminosis D}

Countries within each region are introduced by order of latitude, starting with the countries that extend furthest from the equator.

\section{East Asia and Pacific}

Nutritional rickets is highly prevalent in Mongolia and China. In a study assessing the nutritional status of preschool children living in Ulaanbaatar in Mongolia in the 1990 s, $50 \%$ of 342 randomly selected children had serum 25-hydroxyvitamin D levels $<18 \mathrm{nmol} / 1^{44}$. In a study of 1,277 randomly selected healthy girls aged 12-14 years living in Beijing, serum 25hydroxyvitamin D levels of $<12.5 \mathrm{nmol} / 1$ were reported in $45 \%$ and $7 \%$ of the girls in winter and summer, respectively. The prevalence of rickets in China is reported to be among the highest in the world ${ }^{45}$.

In addition, over $60 \%$ of 504 women aged $18-40$ years living in Kuala Lumpur or Jakarta in Indonesia were reported in 2008 to have serum 25-hydroxyvitamin D levels < $50 \mathrm{nmol} / 1$; ethnicity and dress style predicted serum 25 - hydroxyvitamin D values ${ }^{46}$. Another report in 2008 found that $35 \%$ of 74 Indonesian elderly women living in institutionalized care units in Jakarta or Bekasi in Indonesia had 25- hydroxyvitamin D levels $<75 \mathrm{nmol} / 1^{47}$.

\section{Europe and Central Asia}

In a study of 8,532 post menopausal women with a mean age of 74.2 years from nine European countries, $30 \%$ of 1,544 women from Poland had hypovitaminosis

$\mathrm{D}$ defined as serum 25- hydroxyvitamin D levels of d ${ }^{4} 50 \mathrm{nmol} / 1$; this prevalence level was similar to that found overall for the whole nine-country cohort ${ }^{48}$.By use of the same cut-off value of $50 \mathrm{nmol} / 1$, a prevalence of hypovitaminosis D of $83 \%$ was reported in winter among 274 women aged 60-90 years living in Warsaw, Poland ${ }^{49}$. In a survey of 54 neonates and their mothers in Ankara, Turkey, 46\% of the mothers and $80 \%$ of the neonates had 25-hydroxyvitamin D levels $<25 \mathrm{nmol} / 1$.

\section{Latin America and the Caribbean}

In seven different regions of Argentina, 57\% of 386 elderly indivi duals had serum 25-hydroxyvitamin D levels $<50 \mathrm{nmol} / 1$ at the end of winter. Old age, winter season and low calcium intake were independent predictors for low serum 25- hydroxyvitamin D levels 50 . 


\section{South Asia}

The South Asia region has UVB radiation levels that are sufficient for vitamin D synthesis for 11 to 12 months of the year, but serum 25-hydroxyvitamin D levels of $<25 \mathrm{nmol} / 1$ have been reported in more than $50 \%$ of the infants, children and women studied. For example, in Kabul, Afghanistan, 73\% of 107 preschool children randomly sampled in winter had 25hydroxyvitamin D levels $<20 \mathrm{nmol} / \mathrm{1}^{51}$.

Rickets is commonly reported in Bangladesh, but nutritional calcium deficiency plays a major part. Suboptimal serum 25-hydroxyvitamin D levels $(<25$ $\mathrm{nmol} / 1)$ were described in 189 women living in Dhaka or in Nandail cities, with high prevalence in lactating women of low socioeconomic status and those wearing the Shari that exposes only the face and hands to sunlight ${ }^{52}$. In another survey of women aged 18-60 years in Dhaka, serum 25- hydroxyvitamin D levels were $<40 \mathrm{nmol} / 1$ in $78 \%$ of 36 university students and in $83 \%$ of 30 veiled women. Predictors of low vitamin $\mathrm{D}$ included low parity and lack of time spent outdoors $^{53}$.

High prevalence of hypovitaminosis D has been reported among Indian and Pakistani women and children from different studies ${ }^{54,55}$.

\section{The Middle East and north Africa}

In an international study of women with osteo porosis, the highest prevalence of hypovitaminosis $\mathrm{D}$ was reported in the Middle East. ${ }^{56}$ Eighty per cent of 50 mothers in Tehran and $46 \%$ of 67 mothers in Zanjan had serum 25-hydroxyvitamin D $<25 \mathrm{nmol} / 1$, and low levels of serum 25-hydroxyvitamin D were found in neonates (mean $4.9 \mathrm{nmol} / 1$ and $16.7 \mathrm{nmol} /$ 1 in Tehran and Zanjan, respectively) ${ }^{57,58}$. Serum $25-$ hydroxyvitamin D levels $<20 \mathrm{nmol} / 1$ were common in a study of 963 schoolchildren in Tehran, and these levels were five times more prevalent in girls than in boys $\left(50 \%\right.$ versus $11 \%$, respectively) ${ }^{59}$. Studies in Lebanese adults also reported levels of $<25 \mathrm{nmol} / 1$ in $60 \%$ of 465 women aged 20-59 years in summer ${ }^{60}$.

In a study of North Africa,415 women aged 24-77 years living in Rabat, Morocco, 91\% had 25-hydroxyvitamin D levels $<75 \mathrm{nmol} / 1$. Predictors of low serum 25hydroxyvitamin D levels included female sex, multiparity, menopause, veiling and low calcium and vitamin $\mathrm{D}$ intake ${ }^{61}$.

\section{Conclusion:}

Vitamin D is important for both skeletal and nonskeletal health. It is now well established that many people have vitamin levels that are less than currently recommended for optimal health. Predominant source of vitamin D is cutaneous production through UVB from sun exposure. Latitudes,cultaral dress habits, sun avoidance and sunsreen protection can limit vitamin D production. Gastrointestinal, hepatic and renal diseases contribute to the deficiency, but some serious diseases are the result of vitamin $D$ deficiency. The need for public health-awareness campaigns about the importance of vitamin $\mathrm{D}$ is pressing, specifically in countries where the prevalence of hypovitaminosis D is very high.

\section{References:}

1. Touvier M, Deschasaux M, Montourcy M. Determinants of Vitamin D status in Caucasian Adults: Influence of sun exposure,Dietary intake, Sociodemographic, lifestyle, Anthropometric and Genetic factors. J Invest Dermatol, 2015 Feb; 135(2): 378-88.

2. Holick MF, Chen T C.Vitamin d deficiency: a worlwide problem with health consequences. Am J Cin Nutr, 2008; 87(suppl): 1080s-1086s.

3. Ritu G, Ajay G. Vitamin d deficiency in India: Prevalence, casualties and interventions. Nutrients, February 2014; 6 : 729-775.

4. Arabi A, Rassi EI, Fuleihan G. Hypovitaminosis D in developing countries-prevalence, risk factors and outcomes. Nat Rev Endocrinol. 2010 Oct; 6(10): 55061 [PubMed]

5. Michael F. Holick, M.D. Vitamin D Deficiency. N Engl J Med 2007; 357: 266-81.

6. Arabi A, Rassi EI, Fuleihan G. Hypovitaminosis D in developing countries-prevalence, risk factors and outcomes. Nat Rev Endocrinol. 2010 Oct; 6(10):55061 [PubMed]

7. Holick MF. Vitamin D: a D-lightful health perspective. Nutrition Rev 2008; 66: S182-S194.

8. Pearce SHS, Cheetham T D. Diagnosis and management of vitamin D deficiency. BMJ 2010; 340:b5664

9. Sievenpiper J L, McIntyre L A, Verrill M, Quinton $\mathrm{R}$, Pearce SHS. Unrecognised severe vitamin D deficiency. BMJ 2008 ; 336 : 1371-4.

10. Mussolino ME, Gillum RF: Low bone mineral density and mortality in men and women: The Third National Health and Nutrition Examination Survey Linked Mortality File. Ann Epidemiol 2008, 18:847850 .

11. Suzuki T, Yoshida H: Low bone mineral density at femoral neck is a predictor of increased mortality in elderly Japanese women. Osteoporosis Int 2010, 21:71-79

12. Cantorna MT, Zhu Y, Froicu M, Wittke A. Vitamin D status, 1,25-dihydroxyvitamin D3, and the immune system. Am J Clin Nutr 2004;80:Supp1 6:1717S-1720S. 
13. Ponsonby A-L, McMichael A, van der Mei I. Ultraviolet radiation and autoimmune disease: insights from epidemiological research. Toxicology 2002;181182:71-8

14. VanAmerongen BM, Dijkstra CD, Lips P, Polman CH. Multiple sclerosis and vitamin D: an update. Eur J Clin Nutr 2004;58:1095-109.

15. Munger KL, Levin LI, Hollis BW, Howard NS, Ascherio A. Serum 25-hydroxyvitamin D levels and risk of multiple sclerosis. JAMA 2006;296:2832-8.

16. Munger KL, Zhang SM, O'Reilly E, et al. Vitamin D intake and incidence of multiple sclerosis. Neurology 2004;62:60-5.

17. McAlindon TE, Felson DT, Zhang Y, et al. Relation of dietary intake and serum levels of vitamin D to progression of osteoarthritis of the knee among participants in the Framingham Study. Ann Intern Med 1996;125:353-9.

18. Chiu KC, Chu A, Go VLW, Saad MF. Hypovitaminosis $\mathrm{D}$ is associated with insulin resistance and â cell dysfunction. Am J Clin Nutr 2004;79:820-5.

19. Rostand SG. Ultraviolet light may contribute to geographic and racial blood pressure differences. Hypertension 1997;30:150-6.

20. Krause R, Buhring M, Hopfenmuller W, Holick MF, Sharma AM. Ultraviolet B and blood pressure. Lancet 1998;352:709-10.

21. Zittermann A. Vitamin D and disease prevention with special reference to cardiovascular disease. Prog Biophys Mol Biol 2006;92:39-48.

22. Zittermann A, Schleithoff SS, Tenderich G, Berthold HK, Korfre R, Stehle P. Low vitamin D status: a contributing factor in the pathogenesis of congestive heart failure? J Am Coll Cardiol 2003;41:105-12.

23. Gloth FM III, Alam W, Hollis B. Vitamin D vs. broad spectrum phototherapy in the treatment of seasonal effective disorder. J Nutr Health Aging 1999;3:5-7.

24. Eyles DW, Smith S, Kinobe R, Hewison M, McGrath JJ. Distribution of the vitamin D receptor and 1áhydroxylase in human brain. J Chem Neuroanat 2005;29: 21-30.

25. Zhang R, Naughton D P. Vitamin D in health and disease: Current perspectives Zhang and Naughton Nutrition Journal 2010, 9 : 65 http:// www.nutritionj.com/content/9/1/65

26. Bell NH: Vitamin D metabolism, aging, and bone loss. J Clin Endocrinol Metab 1995; 80:1051.

27. Need AG, Morris HA, Horowitz M, Nordin C: Effects of skin thickness, age, body fat, and sunlight on serum 25-hydroxyvitamin D. Am J Clin Nutr 1993, 58:882-885.

28. Clemens TL, Henderson SL, Adams JS, Holick MF: Increased skin pigment reduces the capacity of skin to synthesis vitamin D3. Lancet 1982;1:74-76.
29. Webb AR, Kline L, Holick MF: Influence of season and latitude on the cutaneous synthesis of vitaminD3: exposure to winter sunlight in Boston and Edmonton will not promote vitamin D3 synthesis in human skin. J Clin Endocrinol Metab 1988, 67:373-378.

30. Lu Z, Chen TC, Kline L, Markestad T, Pettifor J, Ladizesky M, Mautalen C, Holick MF: Photosynthesis of previtamin D3 in cities around the world. In Biologic effects of light. Edited by: Holick MF, Kligman A. Symposium proceedings, October 13-15:1991. Berlin: Walter De Gruyter 1992:48-51.

31. Matsuoka LY, Ide L, Wortsman J, MacLaughlin J, Holick MF: Sunscreens suppress cutaneous vitamin D3 synthesis. J Clin Endocrinol Metab 1987; 64:1165-1168.

32. Holick MF: McCollum Award Lecture, 1994: Vitamin D-new horizons for the 21 st century. Am J Clin Nutr 1994; 60:619-630.

33. Pack AM, Morrell MJ: Epilepsy and bone health in adults. Epilepsy Behav 2004, 5(Suppl. 2):S24-S29.

34. Karaaslan Y, Haznedaroglu S, Ozturk M: Osteomalacia associated with carbamazepine/valproate. Ann Pharmacother 2000; 34:264-265.

35. Dusso AS, Sato T, Arcidiacono MV, AlvarezHernandez D, Yang J, Gonzalez-Suarez I, Tominaga Y, Slatopolsky E: Pathogenic mechanisms for parathyroid hyperplasia. Kidney Int Suppl 2006; 102:S8-S11.

36. Correa P, Segersten U, Hellman P, Akerstrom G, Westin G: Increased 25-hydroxyvitamin D3 1áhydroxylase and reduced 25-hydroxyvitamin D3 24hydroxylase expression in parathyroid tumors - new prospects for treatment of hyperparathyroidism with vitamin D. J Clin Endocrinol Metab 2002; 87:58265829 .

37. Liel Y, Ulmer E, Shary J, Hollis BW, Bell NH: Low circulating vitamin $\mathrm{D}$ in obesity. Calcif Tissue Int 1988; 43:199-201.

38. Compston JE, Vedi S, Ledger JE, Webb A, Gazet JC, Pilkington TRE: Vitamin D status and bone histomorphometry in gross obesity. Am J Clin Nutr $1981 ; 34: 2359-2363$.

39. Hey H, Stockholm KH, Lund BJ, Sorensen OH: Vitamin D deficiency in obese patients and changes in circulating vitamin D metabolites following jejunoileal bypass. Int $\mathrm{J}$ Obes 1982, 6:473-479.

40. Hyldstrup L, Andersen T, McNair P, Breum L, Transbol I: Bone metabolism in obesity: changes related to severe overweight and dietary weightreduction. Acta Endocrinol 1993, 129:393398.

41. MacLaughlin J, Holick MF: Aging decreases the capacity of human skin to produce vitamin D3. J Clin Invest 1985, 76:1536-1538. 
42. Wortsman J, Matsuoka LY, Chen TC, Lu Z, Holick MF: Decreased bioavailability of vitamin D in obesity. Am J Clin Nutr 2000, 72:690-693.

43. Pappa HM, Bern E, Kamin D, Grand RJ. Vitamin D status in gastrointestinal and liver disease. Curr Opin Gastroenterol 2008; 24: 176-183.

44. Kachondham, Y., Dhanamitta, S., Oyunbileg, M. \& Brown, L. Child health and nutritional status in Ulaanbaatar, Mongolia: a preliminary assessment. Asia Pac. J. Public Health 6,226-232 (1992-1993).

45. Du, X. et al. vitamin D deficiency andassociated factors in adolescent girls in Beijing. Am. J. Clin. Nutr. 74, 494-500 (2001).

46. Green, T. J. et al. vitamin D status and its association with parathyroid hormone concentrations in women of child-bearing age living in Jakarta and Kuala Lumpur. Eur. J. Clin.Nutr. 62, 373-378 (2008).

47. Setiati, S. vitamin D status among Indonesian elderly women living in institutionalized care units. Acta Med. Indones. 40, 78-83 (2008).

48. Bruyère, O., Malaise, O., Neuprez, A., Collette, J. \& Reginster, J. Y. Prevalence of vitamin D inadequacy in European postmenopausal women. Curr. Med. Res. Opin. 23, 1939-1944(2007).

49. Napiórkowska, L. et al. Prevalence of low serum vitamin D concentration in an urban population of elderly women in Poland. Pol. Arch. Med. Wewn. 119, 699-703 (2009).

50. Oliveri, B. et al. High prevalence of vitamin D insufficiency in healthy elderly people living at home in Argentina. Eur. J. Clin. Nutr. 58,337-342 (2004).

51. Manaseki-Holland, S., Zulf Mughal, M., Bhutta, Z. \& Qasem Shams, M. vitamin D status of socioeconomically deprived children in Kabul, Afghanistan. Int. J. Vitam. Nutr. Res. 78, 16-20 (2008).
52. Islam, M. Z. et al. vitamin D deficiency: a concern in premenopausal Bangladeshi women of two socioeconomic groups in rural and urban region. Eur. J. Clin. Nutr. 56, 51-56(2002).

53. Islam, M. Z., Akhtaruzzaman, M. \& Lamberg- Allardt, C. Hypovitaminosis D is common in both veiled and nonveiled Bangladeshi women. Asia Pac. J. Clin. Nutr. 15, 81-87 (2006).

54. Zuberi, L. M., Habib, A., Haque, N. \& Jabbar, A. vitamin D deficiency in ambulatory patients. J. Pak. Med. Assoc. 58, 482-484 (2008).

55. Marwaha, R. K. et al. vitamin D and bone mineral density status of healthy schoolchildren in Northern India. Am. J. Clin. Nutr. 82, 477-482(2005).

56. Lips, P. et al. The prevalence of vitamin D inadequacy amongst women with osteoporosis: an international epidemiological investigation. J. Intern. Med. 260, 245-254 (2006).

57. Bassir, M. et al. vitamin D deficiency in Iranian mothers and their neonates: a pilot study. Acta Paediatr. 90, 577-579 (2001).

58. Kazemi, A., Sharifi, F., Jafari, N. \& Mousavinasab, N. High prevalence of vitamin D deficiency among pregnant women and their newborns in an Iranian population. J. Women's Health (Larchmt) 18, 835-839 (2009).

59. Rabbani, A. et al. vitamin D insufficiency among children and adolescents living in Tehran, Iran. $J$. Trop. Pediatr. 55, 189-191 (2009).

60. Fuleihan, G. E. \& Deeb, M. Hypovitaminosis D in a sunny country. N. Engl. J. Med. 340, 1840-1841 (1999).

61. Allali, F. et al. High prevalence of hypovitaminosis D in Morocco: relationship to lifestyle, physical performance, bone markers, and bone mineral density. Semin. Arthritis Rheum. 38, 444-451 (2009). 